National Bureau of bud
ribrary, N. W. Bldg

JUN 291964

\title{
NBS
}

Eechnical Note

No. 216

\section{COMPUTATION OF HANKEL FUNCTIONS}

LESLIE A. BERRY

U. S. DEPARTMENT OF COMMERCE

NATIONAL BUREAU OF STANDARDS 


\section{THE NATIONAL BUREAU OF STANDARDS}

The National Bureau of Standards is a principal focal point in the Federal Government for assuring maximum application of the physical and engineering sciences to the advancement of technology in industry and commerce. Its responsibilities include development and maintenance of the national standards of measurement, and the provisions of means for making measurements consistent with those standards; determination of physical constants and properties of materials; development of methods for testing materials, mechanisms, and structures, and making such tests as may be necessary, particularly for government agencies; cooperation in the establishment of standard practices for incorporation in codes and specifications; advisory service to government agencies on scientific and technical problems; invention and development of devices to serve special needs of the Government; assistance to industry, business, and consumers in the development and acceptance of commercial standards and simplified trade practice recommendations; administration of programs in cooperation with United States business groups and standards organizations for the development of international standards of practice; and maintenance of a clearinghouse for the collection and dissemination of scientific, technical, and engineering information. The scope of the Bureau's activities is suggested in the following listing of its four Institutes and their organizational units.

Institute for Basic Standards. Electricity. Metrology. Heat. Radiation Physics. Mechanics. Applied Mathematics. Atomic Physics. Physical Chemistry. Laboratory Astrophysics. * Radio Standards Laboratory: Radio Standards Physics; Radio Standards Engineering. * * Office of Standard Ref. erence Data.

Institute for Materials Research. Analytical Chemistry. Polymers. Metallurgy. Inorganic Materials. Reactor Radiations. Cryogenics. ${ }^{* *}$ Office of Standard Reference Materials.

Central Radio Propagation Laboratory.** Ionosphere Research and Propagation. Troposphere and Space Telecommunications. Radio Systems. Upper Atmosphere and Space Physics.

Institute for Applied Technology. Textiles and Apparel Technology Center. Building Research. Industrial Equipment. Information Technology. Performance Test Development. Instrumentation. Transport Systems. Office of Technical Services. Office of Weights and Measures. Office of Engineering Standards. Office of Industrial Services.

* NBS Group, Joint Institute for Laboratory Astrophysics at the University of Colorado.

* Located at Boulder, Colorado. 


\title{
NATIONAL BUREAU OF STANDARDS Eechnical Mote 216 Issued June 12, 1964
}

\section{COMPUTATION OF HANKEL FUNCTIONS}

\author{
Leslie A. Berry \\ Central Radio Propagation Laboratory \\ National Bureau of Standard's \\ Boulder, Colorado
}

NBS Technical Notes are designed to supplement the Bureau's regular publications program. They provide a means for making available scientific data that are of transient or limited interest. Technical Notes may be listed or referred to in the open literature. 
Foreword

This work was sponsored in part by Rome Air Development Center, Griffiss Air Force Base, New York, in connection with Tasks 4 and 5 of D. O. No. AF -30(602) -2488 , and in part by NBS Project No. 85111 . 


\section{Contents}

Foreword . . . . . . . . . . . . . . . . . . ii

Abstract . . . . . . . . . . . . . . . . . . . $1^{\circ}$

1. Introduction . . . . . . . . . . . . . . . . 1

2. Complex Order, v or z Large . . . . . . . . . 2

2. 1. Determination of $\eta$. . . . . . . . . . . . 4

3. Real Orde $\mathrm{r}$. . . . . . . . . . . . . . 5

3. 1. Small $|z|$. . . . . . . . . . . . . 5

3. 2. Large $|z|$. . . . . . . . . . . . . 6

3.3. The Convergence Factor . . . . . . . . . . 7

4. Discussion of Results . . . . . . . . . . . . . 9

5. Conclusions . . . . . . . . . . . . . . . . 10

6. References . . . . . . . . . . . . . . 11

7. List of Symbols . . . . . . . . . . . . . . . 13

Table 1 . . . . . . . . . . . . . . . . . . . 14

Figures 1 through 5 . . . . . . . . . . . . . . . 15 

Methods of computing solutions to Bessel's equation,
$\mathrm{z}^{2} \frac{\mathrm{d}^{2} \mathrm{y}}{\mathrm{d} \mathrm{z}^{2}}+\mathrm{z} \frac{\mathrm{dy}}{\mathrm{dz}}+\left(\mathrm{z}^{2}-\mathrm{v}^{2}\right) \mathrm{y}=0$, for complex $\mathrm{v}$ and $\mathrm{z}$, and for small, real $\mathrm{v}$, are given in detail. The methods are most suitable for use on an electronic digital computer. With a computer which carries eight decimal digits, the methods presented for small, real v will return at least six correct significant digits for all $\mathrm{z}$. When $\mathrm{v}$ and $\mathrm{z}$ are both complex, the accuracy depends on $|\mathrm{z}|$ (since asymptotic forms are used) and the ratio $v / z$. Relative error curves are shown as a function of $|\mathrm{v} / \mathrm{z}|$ parametric in $|\mathrm{z}|$. For $\mathrm{v}$ sufficiently far from $\mathrm{z}$, seven correct digits are obtained, which for $v \cong z$, the relative error is of the order $10^{-2} /|z|$.

\section{Introduction}

Solutions to electromagnetic or sound-wave problems in spherical or cylindrical co-ordinates usually involve solutions of Bessel's equation, $z^{2} \frac{d^{2} y}{d z^{2}}+z \frac{d y}{d z}+\left(z^{2}-v^{2}\right) y=0$. The Hankel functions [Watson, 1958] $\mathrm{H}_{\mathrm{v}}^{(1)}(\mathrm{z})$ and $\mathrm{H}_{\mathrm{v}}^{(2)}(\mathrm{z})$ a re one set of linearly independent solutions. Other solutions can be written in terms of these solutions [see (19)]. The superscript indicates the "kind, " $\mathrm{v}$, the "order, " and $z$, the "argument" of the functions, and either v, or $z$, or both may be complex. The purpose of this paper is to present in one place detailed instructions for computing the Hankel functions on an electronic digital computer, and to investigate quantitatively the relative errors incurred. No new mathematical development is involved, but since considerable algebraic reduction and systemization of scattered results were necessary, publication of the results seems desirable.

Section 2 details methods of computing $\mathrm{H}_{\mathrm{v}}(\mathrm{z})$ when $\mathrm{v}$ and $\mathrm{z}$ are complex. If $\mathrm{v} \cong \mathrm{z}, \mathrm{H}_{\frac{1}{3}}(\mathrm{z})$ must be computed accurately, so techniques are given in section $3^{\frac{3}{3}}$ for computing $\mathrm{H}_{v}(\mathrm{z})$ when $\mathrm{v}$ is real and small and $z$ is unrestricted. The accuracy of the methods is discussed in section 4 . 


\section{Complex Order, v or z Large}

In this section, it is assumed only that eithe $\mathrm{r} v$ or $\mathrm{z}$ is large. What is meant by "large" will be discussed quantitatively in section 4 , but the asymptotic expressions used here [(1) and table 1] accurately describe the qualitative behavior of the Hankel functions over most of the $\mathrm{v}$ and $\mathrm{z}$ planes, since the minimum relative error is about one per cent for $|v| \cong|z| \cong 1$ (figure 5).

Two approximations are used. In the first, which will be called the Hankel approximation [Fok, 1934],

$$
H_{v}^{(k)}(z) \cong \exp \left[(-1)^{k-1} i \pi / 6\right] \sqrt{1-\eta \operatorname{coth} \eta} H_{\frac{1}{3}}^{(k)}(-i \xi), k=1,2,
$$

whe re

$$
\xi=\mathrm{v}(\tanh \eta-\eta)
$$

$\cosh \eta=v / z$, and $|\arg v|<\pi / 2$ [Olver, 1954]. For $|\arg v|>\pi / 2$, (3) (9) is used.

The principal square root is used; i. e.,

$$
\arg \sqrt{w}=\frac{1}{2} \arg w
$$

and

$$
-\pi<\arg w \leqq \pi \text {. }
$$

for $\mathrm{v} / \mathrm{z} \cong 1[\mathrm{Fok}, 1946]$,

$$
-i \xi=\frac{z}{3}\left(1-\frac{v^{2}}{z^{2}}\right)^{3 / 2}\left[1+\frac{2}{5}\left(1-\frac{v^{2}}{z^{2}}\right)+0\left(1-\frac{v^{2}}{z^{2}}\right)^{2}\right] .
$$

The first term on the right has been used extensively as an approximation to $-i \xi$ in radio propagation theory [Fok, 1946; Bremmer, $1949]$. 
The second approximation, called the Debye approximation, will be written in terms of [Watson, 1958]

$$
S_{v}^{(k)}(z) \cong \frac{\exp \left[(-1)^{k-1}\left(\xi-\frac{\pi}{4} i\right)\right]}{\sqrt{-\frac{\pi}{2} i v \tanh \eta}} \sum_{m=0}^{\infty} \frac{\Gamma\left(m+\frac{1}{2}\right)}{\Gamma\left(\frac{1}{2}\right)} \frac{(-1)^{(k-1)}\left(\frac{v}{2} \tanh \eta\right)_{m}}{(x}
$$

The combination of $S_{v}^{(1)}(z)$ and $S_{v}^{(z)}(z)$ to be used depends on the location of $\mathrm{v} / \mathrm{z}$ in the complex plane. The first four $A_{m}$ are [British Association Mathematical Tables, 1952]:

$$
\begin{aligned}
& \mathrm{A}_{0}=1, \\
& \mathrm{~A}_{1}=\frac{1}{8}-\frac{5}{24} \operatorname{coth}^{2} \eta, \\
& \mathrm{A}_{2}=\frac{3}{128}-\frac{77}{576} \operatorname{coth}^{2} \eta+\frac{385}{3456} \operatorname{coth}^{4} \eta, \\
& \mathrm{A}_{3}=\frac{5}{1024}-\frac{1521}{25600} \operatorname{coth}^{2} \eta+\frac{17017}{138240} \operatorname{coth}^{4} \eta-\frac{17017}{248832} \operatorname{coth}^{6} \eta .
\end{aligned}
$$

Forms for $\mathrm{A}_{4}--\mathrm{A}_{7}$ can also be found in the above reference. In (5), use the principal square root. The series in (5) can be written

$$
\sum_{m=0}^{\infty} \frac{\Gamma\left(m+\frac{1}{2}\right)}{\Gamma\left(\frac{1}{2}\right)} \frac{A_{m}}{\left( \pm \frac{1}{2} v \tanh \eta\right)^{m}}=1 \pm \frac{A_{1} \operatorname{coth} \eta}{v}+\frac{3 A_{2} \operatorname{coth}^{2} \eta}{v^{2}} \pm \frac{15 A_{3} \operatorname{coth}^{3} \eta}{v^{2}}+\cdots
$$

This is an asymptotic series and should be truncated at the smallest term; i.e., all terms preceding the smallest term should be summed.

The regions of the plane to be considered are shown in figure 1 , and the expressions for $\mathrm{H}_{\mathrm{v}}(\mathrm{z})$ are given in table 1 . These expressions are correct only if $\operatorname{Re}(z) \geq 0$, but if $\operatorname{Re}(z)<0$, the formulas [Watson, 1958] 


$$
H_{v}^{(1)}\left(z e^{k} \pi^{1}\right)=\frac{\sin (1-k) \pi v}{\sin \pi v} H_{v}^{(1)}(z)-e^{-v \pi 1} \frac{\sin k \pi v}{\sin \pi v} H_{v}^{(2)}(z)
$$

and

$$
H_{v}^{(2)}\left(z e^{k \pi 1}\right)=\frac{\sin (1+k) \pi v}{\sin \pi v} H_{v}^{(2)}(z)+e^{v \pi 1} \frac{\sin k \pi v}{\sin \pi v} H_{v}^{(1)}(z) \text {, }
$$

where $k$ is any integer, can be used to evaluate the desired function. Although expressions can be derived for $\mathrm{H}_{\mathrm{v}}(\mathrm{z})$ in regions $6 \mathrm{~b}, 7 \mathrm{~b}$, and 9, it is simpler to compute $H_{-v}(z)$ [so that $-v / z$ is in $6 a, 7 a$, or 8] and use [Watson, 1958]

$$
H_{v}^{(k)}(z)=\exp \left[(-1)^{k} v \pi i\right] H_{-v}^{(k)}(z), k=1,2 .
$$

\section{1. Determination of $\eta$}

Directions for computing $\eta$ and for determining the correct region of the plane, figure 1 , will now be given. Let $\eta=\alpha+i \beta$, where $\alpha$ and $\beta$ are real. Then $\alpha+i \beta=\cosh ^{-1} \mathrm{v} / \mathrm{z}$. The infinitely many-valued function, $\cosh ^{-1}$, is made single valued by requiring that $0 \leq \beta<\pi$ [Watson, 1958]. $\beta=0$ if $v / z$ is real and $v / z \geq 1$. Specifically

$$
\alpha=-\log \left(\left|\frac{\mathrm{v}}{\mathrm{z}} \pm \sqrt{\frac{\mathrm{v}^{2}}{\mathrm{z}^{3}}-1}\right|\right)
$$

The sign is chosen so that $\alpha$ has the same $\operatorname{sign}$ as $\operatorname{Im}(v / z)$. If $\operatorname{Im}(v / z)=0$, and $|v / z|>1$, the positive sign is chosen; if $|v / z| \leq 1$, $\eta=\operatorname{Cos}^{-1} \mathrm{v} / \mathrm{z}$. Then

$$
\beta=\operatorname{Cos}^{-1}[\operatorname{Re}(v / z) / \cosh \alpha]
$$

These directions are exact for use in (5), and are valid for (1) over most of the plane. (For a discussion of the region of validity for the Hankel approximation, consult Olver [1954].) For (1), when $v \cong z$, $\arg (-i \xi)$ can be determined by examining the first term of $(4)$; when $v$ is not near $z$, the Debye approximation is superior.

The $\mathrm{m}$ in table 1 is the largest integer less than

$$
\{(1-\alpha \tanh \alpha) \tan \beta+\beta\} / \pi \text {. }
$$


Now, let

$$
f(\alpha, \beta)=1-\beta \cot \beta-\alpha \tanh \alpha .
$$

The signs of $f(\alpha, \beta), f(\alpha, \beta)+\pi \cot \beta, \operatorname{Re}(v / z)$, and $\operatorname{Im}(v / z)$ uniquely determine in which of the regions shown in figure $1 \mathrm{v} / \mathrm{z}$ is located. Column 2 of table 1 shows how the region can be determined.

\section{Real Order}

To use (1), a routine for computing $\mathrm{H}_{\frac{1}{3}}(\mathrm{z})$ must be available. In this section, methods are given for computing $H_{v}(z)$ for small, real v. The restriction that $\mathrm{v}$ be real is probably not necessary if $\mathrm{z}^{v}$ is carefully defined, but it is retained in this section.

\section{1. Small $|z|$}

If $\mathrm{v}$ is not an integer [Watson, 1958]

$$
H_{v}^{(k)}(z)=(-1)^{k}\left\{\exp \left[(-1)^{k} v \pi i\right] J_{v}(z)-J_{-v}(z)\right\} / i \sin v \pi, k=1,2,
$$

where $J_{v}(z)$ is the Bessel function of the first kind, defined by [Watson, 1958 ]

$$
\begin{aligned}
J_{v}(z) & =\sum_{m=0}^{\infty} \frac{(-1)^{m}(z / 2)^{v+2 w}}{m ! \Gamma(v+m+1)} \\
& =\frac{(v / 2)^{v}}{\Gamma(v+1)}\left(1-\frac{(z / 2)^{2}}{1 !(v+1)}+\frac{(z / 2)^{4}}{2 !(v+1)(v+2)}-\frac{(z / 2)^{6}}{3 !(v+1)(v+2)(v+3)}+\cdots .\right.
\end{aligned}
$$

$\mathrm{J}_{\mathrm{v}}(\mathrm{z})$ is made single-valued by specifying $\arg (\mathrm{z} / 2)^{\mathrm{v}}=\mathrm{v} \arg (\mathrm{z} / 2)$ for $\Delta-2 \pi<\arg (z / 2) \leq \Delta$. Ordinarily, $\Delta=\pi$, but may have different values for some applications.

If $\mathrm{v}$ is an integer, (13) is indeterminate. To compute $H_{n}(z)$ for integral $n$ and small $z$, compute $J_{\circ}(z)$ and $J_{1}(z)$ using (14) and then find the Bessel function of the second kind, $Y_{0}(z)$, from [Watson, 1958] 


$$
Y_{0}(z)=\frac{2}{\pi}\left[\left(\gamma+\log \left(\frac{z}{2}\right)\right) J_{0}(z)+\sum_{m=1}^{\infty} \frac{(z / 2)^{m} J_{m}(z)}{m \cdot m !}\right]
$$

where $\gamma$ is Euler's constant, $\gamma=.5772156649 \cdots$. The $J_{m}(z), m>1$ are found with the recurrence formula [Watson, 1958].

$$
J_{\square}+I(z)=\frac{2 m}{z} J_{m}(z)-J_{u-I}(z) .
$$

Then [Watson, 1958]

$$
Y_{I}(z)=\left\{J_{I}(z) Y_{0}(z)+\frac{2}{\pi z}\right\} / J_{0}(z)
$$

and

$$
Y_{m+1}(z)=\frac{2 m}{z} Y_{m}(z)-Y_{m-1}(z)
$$

Finally,

$$
H_{n}^{(k)}(z)=J_{n}(z)+(-1)^{k-1} i Y_{n}(z)
$$

\section{2. Large $|z|$}

As $|z|$ gets large, (14) converges slowly and loses precision. More serious is the precision lost in (13) and (19), since in half of the $\mathrm{z}$-plane the terms on the right are nearly negatives of each other when $\operatorname{Im}(z)$ is large. For example, four significant digits are lost in (19) when $n=1, z=5 \exp \left(i 5^{\circ}\right)$. It is therefore necessary to use the asymptotic series [Watson, 1958].

$$
\begin{aligned}
& H_{v}^{(1)}(z)=\frac{\exp \left(i z-i\left(v+\frac{1}{2}\right) \pi / 2\right)}{\sqrt{\pi z / 2}} T_{v}(-2 i z),(-\pi<\arg z<2 \pi), \\
& H_{v}^{(2)}(z)=\frac{\exp \left(-i z+i\left(v+\frac{1}{2}\right) \pi / 2\right)}{\sqrt{\pi z / 2}} T_{v}(2 i z),(-2 \pi<\arg z<\pi),
\end{aligned}
$$


where

$$
T_{v}(z)=1+\sum_{n=1}^{\infty} \frac{\left(4 v^{2}-1^{2}\right)\left(4 v^{2}-3^{2}\right) \cdots\left(4 v^{2}-(2 n-1)^{2}\right)}{n !(4 z)^{n}}
$$

Unless $v=n+\frac{1}{2}$, for integral $n, T_{v}(z)$ is an asymptotic series and should be stopped at the smallest term. If $v=n+\frac{1}{2}, T_{v}(z)$ terminates, and (20) is the finite series for $H_{n+\frac{1}{2}}(z)$.

Using a computer which carries eight decimal digits in floating point operations, about four correct significant digits in $H_{v}(z)$ are obtained over all of the $z$-plane, using the methods presented above. This accuracy is increased to at least six digits if Dingle's [1958, 1959 ] convergence factor is used in (21), as described below.

\section{3. The Convergence Factor}

In a series of papers, R. B. Dingle has developed a general theory [Dingle, 1958] of convergence factors and has applied this theory to many special functions [Dingle, 1958, 1959]. When the product of a convergence factor, $C_{n}(z)$, and the $n$th term of an asymptotic series is added to the previous $n$ - 1 terms, the sum is the exact sum of the entire series. In practice, of course, the sum is not "exact, "but the use of a convergence factor does significantly extend the range of application of an asymptotic series.

In the particular case of the Hankel functions, (21) is written:

$$
\begin{aligned}
T_{v}(z)= & 1+\sum_{n=1}^{N-1} \frac{\left(4 v^{2}-1^{2}\right)\left(4 v^{2}-3^{2}\right) \cdots\left(4 v^{2}-(2 n-1)^{2}\right)}{n !(4 z)^{n}} \\
& +\frac{\left(4 v^{2}-1^{2}\right) \cdot \cdots\left(4 v^{2}-(2 N-1)^{2}\right)}{N !(4 z)^{N}} C_{N}(v, z),
\end{aligned}
$$

where $\mathrm{N}$ is chosen so that the term corresponding to $\mathrm{N}-1$ is the smallest term of (21). Then, [Dingle, 1959] for $s=N-v-\frac{1}{2}$, 


$$
\begin{gathered}
C_{N}(v, z)=\sum_{t=0}^{\infty} \frac{\Gamma\left(v+\frac{1}{2}\right) \Gamma\left(N+v-t+\frac{1}{2}\right)}{\Gamma\left(v-t+\frac{1}{2}\right) \Gamma\left(N+v+\frac{1}{2}\right)}(-z)^{t} \Lambda_{s}^{(t)}(z) \\
=\Lambda_{s}^{(0)}(z)-\frac{\left(v-\frac{1}{2}\right) z}{\left(N+v-\frac{1}{2}\right)} \Lambda_{s}^{(1)}(z)+\frac{\left(v-\frac{1}{2}\right)\left(v-\frac{3}{2}\right) z^{2}}{\left(N+v-\frac{1}{2}\right)\left(N+v-\frac{3}{2}\right)} \Lambda_{s}^{(z)}(z)-\cdots,
\end{gathered}
$$

where [Dingle, 1958]

$$
\begin{gathered}
\Lambda_{s}^{(0)}(z)=\frac{1}{\Gamma(s+1)} \int_{0}^{\infty} \frac{x^{s} e^{-x} d x}{1+x / z}, \\
z \Lambda_{s}^{(1)}(z)=(s+z+1) \Lambda_{s}^{(0)}(z)-z, \\
2 z \Lambda_{s}^{(z)}(z)=(s+z) \Lambda_{s}^{(1)}(z)+\Lambda_{s}^{(0)}(z)-1,
\end{gathered}
$$

and

$$
\operatorname{tz} \Lambda_{s}^{(t)}(z)=(s+z+2-t) \Lambda_{s}^{(t-1)}(z)+\Lambda_{s}^{(t-z)}(z), t>2 .
$$

When $|s| \gg 1$, or $|z| \gg 1$, and $|\arg z|<3 \pi / 4$ [Dingle, 1958],

$$
\Lambda_{\mathrm{s}}^{(0)}(z) \cong \frac{z}{s+z}\left(1-\frac{z}{(s+z)^{2}}-\frac{z(s-2 z)}{(s+z)^{4}}-\frac{z\left(s^{2}-8 s z+6 z^{2}\right)}{(s+z)^{6}}-\cdots\right) .
$$

Otherwise, $\Lambda_{s}^{(0)}(z)$ can be found by numerical integration. For the general routine used with this paper, $\Lambda_{s}^{(0)}(z)$ was found with an eight point Gaussian quadrature formula:

$$
\int_{0}^{\infty} x^{5} e^{-x} f(x) d x \cong \sum_{k=1}^{8} w_{k} f\left(x_{k}\right)
$$

since $s \geq 5$ for use in (24). The $W_{k}$ and $x_{k}$ are taken from Rabinowitz and Weiss [1959]. Then $C_{N}(v, z)$ is approximated by the first four terms of (23). 


\section{Discussion of Results}

Fortran subroutines were written to compute $\mathrm{H}_{\frac{1}{3}}(\mathrm{z})$ and $\mathrm{H}_{\frac{2}{3}}(\mathrm{z})$ and $\mathrm{H}_{\mathrm{n}}(\mathrm{z})$ using the methods of section 3. The values for $\mathrm{H}_{\frac{1}{3}}(\mathrm{z})$ and $\mathrm{H}_{\frac{2}{3}}(\mathrm{z})$ were checked against the Tables of Modified Hankel Functions of Order One-Third and Their Derivatives [The Staff of the Computation Laboratory, 1945]. The computed values agree with the tabular values to at least six significant digits where the tables give six digits. (The tables give eight decimal places.) The values of $H_{n}(z)$ computed by the routine were checked against NBS tables for $J_{0}(z)$ and $J_{1}(z)$, [Mathematical Tables Project, 1947] and $Y_{0}(z)$ and $Y_{1}(z)$ [Computation Laboratory, 1950] and gave comparable results.

The Debye and Hankel approximations were programmed separately and checked for real order by comparing the values they returned with the correct (to at least six significant digits) answers given by the methods of section 3. A subroutine valid for small, complex $v$ and $z$ was obtained from SHARE [Goldstein, Kresge; and Chen, 1960], and the asymptotic routines described here returned answers correct to the expected accuracy, providing an independent check of the routines' logic.

\section{Defining}

$$
\text { Relative error }=\left|\frac{\text { answer }- \text { approximation }}{\text { answer }}\right| \text {, }
$$

figures 2, 3, and 4 show relative error curves for both approximations as functions of $|\mathrm{v} / \mathrm{z}|$, parametric in $|\mathrm{z}|$ for $|\arg \mathrm{z}|=0^{\circ}, 5^{\circ}$, and $15^{\circ}$, respectively. It is apparent from these curves that the Debye approximation is the better except when $v \cong z$. Even when $|v / z|=1$, if $|\arg \mathrm{v} / \mathrm{z}|$ and $|\mathrm{z}|$ are not small, the Debye approximation is superior, as shown in figure 5. Nevertheless, any general routine for computing $\mathrm{H}_{\mathrm{v}}(\mathrm{z})$ must include the Hankel approximation. The relative-error curves all show that, for any $z$, there is an $\varepsilon>0$ such that, if $|v-z|<\varepsilon$, the Debye approximation is useless.

If series (7) is truncated at the smallest term, the relative error in the Debye approximation is of the order of the magnitude of that term. Examination of figures 2 through 5 yields an empirical formula, 


$$
\mid \text { relative error }\left|\cong 10^{-2} /\right| z \mid \text {. }
$$

for the Hankel approximation (1).

A general routine for $\mathrm{H}_{\mathrm{v}}(\mathrm{z})$ was written, incorporating both the Debye and Hankel approximations. The routine uses the Debye approximation unless the smallest term of series (7) is larger than $10^{-2} /|z|$, in which case the Hankel approximation is used. This routine and other computer routines described in this paper are available from SHARE [Berry, 1963].

\section{Conclusions}

Using an electronic computer, solutions to Bessel's equation of real order and complex argument can be computed very accurately. Even when the order is complex, computations can be made sufficiently accurate for most applications. The subroutines incorporating the methods should be valuable in radio and sound wave computations. 


\section{References}

Berry, L. A. (1963), SHARE subroutines HNKL and HF13, SHARE Distribution Nos. 1488 and 1489. Also order SHARE Distribution Nos. $1490--1493$ for necessary subroutines.

Bremmer, H. (1949), Terrestrial radio waves; theory of propagation (Elsevier Publ. Co., New York, N. Y.).

Computation Laboratory, NBS (1950), Tables of the Bessel functions $Y_{0}(z)$ and $Y_{1}(z)$ for complex arguments (Columbia University Press, N. Y.).

British Association Mathematical Tables (1952), Bessel functions of positive integer order, 10 (Cambridge at the University Press).

Dingle, R. B. (Apr. 1958), Asymptotic expansions and converging factors, Parts I-III, Proc. Roy. Soc. (London) Ser. A: 244, 456-491; (Jan. 1959), Parts IV, V, Proc. Roy. Soc. (London) Ser. A: 249, 270-292.

Fok, V. A. (1934), New asymptotic expression for the Bessel functions, Doklady, A. N. USSR 1, 3, 97-99.

Fok, V. A. (1946), Diffraction of radio waves a round the earth's surface (Publishers of the Academy of Science, USSR, Moscow).

Goldstein, M., M. Kresge, and S. Chen (1960), NUBES 3, SHARE Distribution No. 469.

Mathematical Tables Project, NBS (1947), Tables of the Bessel functions $J_{0}(z)$ and $J_{1}(z)$ for complex arguments, second ed. (Columbia University Press, N. Y.).

Olver, F. W. J. (1954), The asymptotic expansion of Bessel functions of large order, Phil. Trans. Roy. Soc. (London), Ser. A: 247, 328-368.

Rabinowitz, P., and G. Weiss (1959), Tables of abscissa and weights for numerical evaluation of integrals of the form $\int_{0}^{\infty} e^{-x} x^{n} f(x) d x$,
MTAC, XIII, 285-294. 
The Staff of the Computation Laboratory (1945), Tables of the modified Hankel functions of order one-third and of their derivatives (Harvard University Press, Cambridge, Massachusetts).

Watson, G. N. (1958), A treatise on the theory of Bessel functions, second ed. (Cambridge at the University Press). 


\section{List of Symbols}

$\mathrm{H}_{v}^{(\mathrm{k})}(\mathrm{z}) \quad$ Hankel function of argument $\mathrm{z}$, order $\mathrm{v}$, and kind $\mathrm{k}$, $k=1,2$.

$J_{v}(z) \quad$ Bessel function of the first kind, of argument $z$ and order v.

$Y_{v}(z) \quad$ Bessel function of the second kind, of argument $z$ and order $v$, sometimes called Neumann's function and denoted $\mathrm{N}_{\mathrm{v}}(\mathrm{z})$.

$T_{v}(z) \quad$ The series defined in (21).

$\eta=\alpha+i \beta=\cosh ^{-1} \frac{v}{z}$

$S_{v}^{(k)}(z) \quad$ The series defined in (5).

A $\quad$ The coefficient of $S_{v}^{(k)}(z)$, see (6).

$f(\alpha, \beta)=1-\beta \cot \beta-\alpha \tanh \alpha$

$m=\quad$ Largest interger less than $\{(1-\alpha \tanh \alpha) \tan \beta+\beta\} / \pi$.

$\mathrm{C}_{\mathrm{N}}(\mathrm{z}) \quad$ Convergence factor for asymptotic series, see section 3.3. 


\begin{tabular}{|c|c|c|c|}
\hline Region & $\begin{array}{l}\text { Determined } \\
\text { by }\end{array}$ & $\mathrm{H}_{\mathrm{v}}^{(1)}(\mathrm{z})$ & $\mathrm{H}_{\mathrm{v}}^{(2)}(\mathrm{z})$ \\
\hline 1 & $\begin{array}{l}f(\alpha, \beta) \geq 0 \\
f(\alpha, \beta)+\pi \cot \beta \geq 0\end{array}$ & $S_{v}^{(1)}(z)$ & $\mathrm{S}_{\mathrm{v}}^{(2)}(\mathrm{z})$ \\
\hline 2 & $\begin{array}{l}f(\alpha, \beta)<0 \\
f(\alpha, \beta)+\pi \cot \beta \geq 0 \\
\operatorname{Im}\left(\frac{v}{z}\right)<0\end{array}$ & $S_{v}^{(1)}(z)-S_{v}^{(2)}(z)$ & $\mathrm{S}_{\mathrm{v}}^{(2)}(\mathrm{z})$ \\
\hline 3 & $\begin{array}{l}\mathrm{f}(\alpha, \beta)<0 \\
\mathrm{f}(\alpha, \beta)+\pi \cot \beta \geq 0 \\
\operatorname{Im}\left(\frac{\mathrm{v}}{\mathrm{z}}\right)<0\end{array}$ & $S_{v}^{(1)}(z)$ & $S_{v}^{(2)}(z)-S_{v}^{(1)}(z)$ \\
\hline 4 & $\begin{array}{l}f(\alpha, \beta) \geq 0 \\
f(\alpha, \beta)+\pi \cot \beta<0 \\
\operatorname{Im}(v / z)>0\end{array}$ & $S_{v}^{(1)}(z)$ & $S_{v}^{(2)}(z)-e^{2 v \pi i} S_{v}^{(1)}(z)$ \\
\hline 5 & $\begin{array}{l}f(\alpha, \beta) \geq 0 \\
f(\alpha, \beta)+\pi \cot \beta<0 \\
\operatorname{Im}(v / z)<0\end{array}$ & $S_{v}^{(1)}(z)-e^{-2 v \pi i} S_{v}^{(2)}(z)$ & $S_{v}^{(2)}(z)$ \\
\hline $6 a$ & $\begin{array}{l}f(\alpha, \beta)<0 \\
f(\alpha, \beta)+\pi \cot \beta<0 \\
\operatorname{Im}(v / z)>0 \\
\operatorname{Re}(v / z) \geq 0\end{array}$ & {$\left[1+e^{(m+1) v \pi i} \frac{\sin m v \pi}{\sin v \pi}\right] S_{v}^{(1)}(z)-S_{v}^{(2)}(z)$} & $S_{V}^{(2)}(z)+e^{(m+1)} v \pi i \frac{\sin m v \pi}{\sin v \pi} S_{v}^{(1)}(z)$ \\
\hline $6 \mathrm{~b}$ & $\begin{array}{l}\mathrm{f}(\alpha, \beta)<0 \\
\mathrm{f}(\alpha, \beta)+\pi \cot \beta<0 \\
\operatorname{Im}(\mathrm{v} / \mathrm{z})>0 \\
\operatorname{Re}(\mathrm{v} / \mathrm{z})<0\end{array}$ & $\begin{array}{l}\text { Compute } \mathrm{H}_{-\mathrm{v}}{ }^{(2)}(\mathrm{z}) \text { and } \\
\text { use (9) }\end{array}$ & $\begin{array}{l}\text { Compute } \mathrm{H}_{-\mathrm{v}}^{(1)}(\mathrm{z}) \text { and } \\
\text { use (9) }\end{array}$ \\
\hline $7 \mathrm{a}$ & $\begin{array}{l}\mathrm{f}(\alpha, \beta)<0 \\
\mathrm{f}(\alpha, \beta)+\pi \cot \beta<0 \\
\operatorname{Im}(\mathrm{v} / \mathrm{z})<0 \\
\operatorname{Re}(\mathrm{v} / \mathrm{z})<0\end{array}$ & $S_{v}^{(1)}(z)-e^{-(m+1) v \pi i} \frac{\sin m v \pi}{\sin v \pi} S_{v}^{(2)}(z)$ & {$\left[1+e^{-(m+1) v \pi i} \frac{\sin m v \pi}{\sin v \pi}\right] S_{v}^{(2)}(z)-S_{v}^{(1)}(z)$} \\
\hline $7 \mathrm{~b}$ & $\begin{array}{l}\mathrm{f}(\alpha, \beta)<0 \\
\mathrm{f}(\alpha, \beta)+\pi \cot \beta<0 \\
\operatorname{Im}(\mathrm{v} / \mathrm{z})<0 \\
\operatorname{Re}(\mathrm{v} / \mathrm{z})<0\end{array}$ & $\begin{array}{l}\text { Compute } \mathrm{H}_{-\mathrm{v}}^{(2)}(\mathrm{z}) \text { and } \\
\text { use (9) }\end{array}$ & $\begin{array}{l}\text { Compute } \mathrm{H}_{-\mathrm{v}}^{(1)}(\mathrm{z}) \text { and } \\
\text { use (9) }\end{array}$ \\
\hline 8 & $\begin{array}{l}\operatorname{Im}(v / z)=0 \\
\operatorname{Re}(v / z) \geq 1\end{array}$ & $\frac{1}{2} S_{v}^{(1)}(z)-S_{v}^{(2)}(z)$ & $\frac{1}{2} S_{V}^{(1)}(z)+S_{v}^{(2)}(z)$ \\
\hline 9 & $\begin{array}{l}\operatorname{Im}(v / z)=0 \\
\operatorname{Re}(v / z)<-1\end{array}$ & $\begin{array}{l}\text { Compute } H_{-v}^{(2)}(z) \text { and } \\
\text { usë (9) }\end{array}$ & $\begin{array}{l}\text { Compute } \mathrm{H}_{-\mathrm{v}}^{(2)}(\mathrm{z}) \text { and } \\
\text { use (9) }\end{array}$ \\
\hline
\end{tabular}

Table 1 


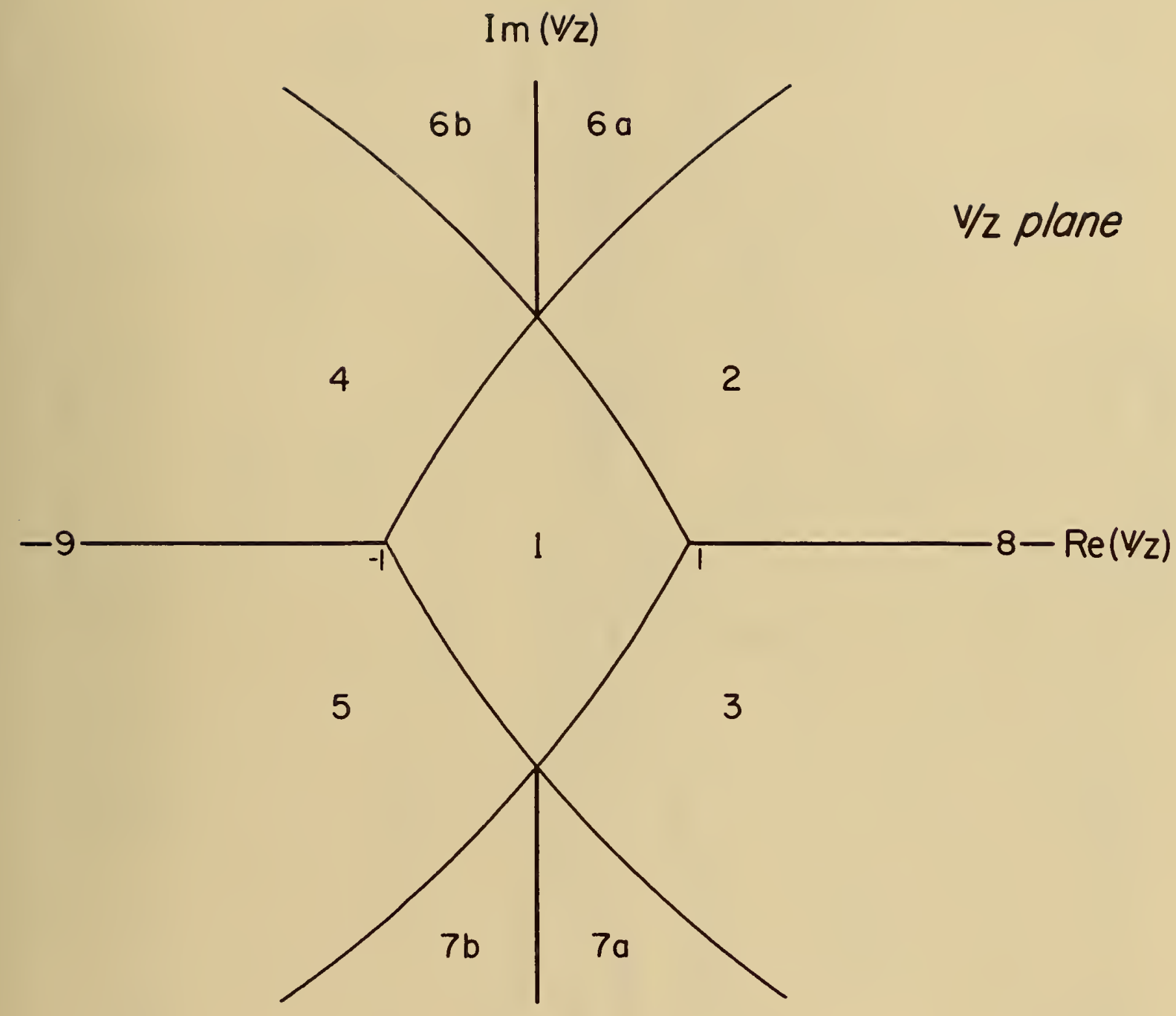

Figure 1. Regions of the $\mathrm{v} / \mathrm{z}$ plane (table 1). 


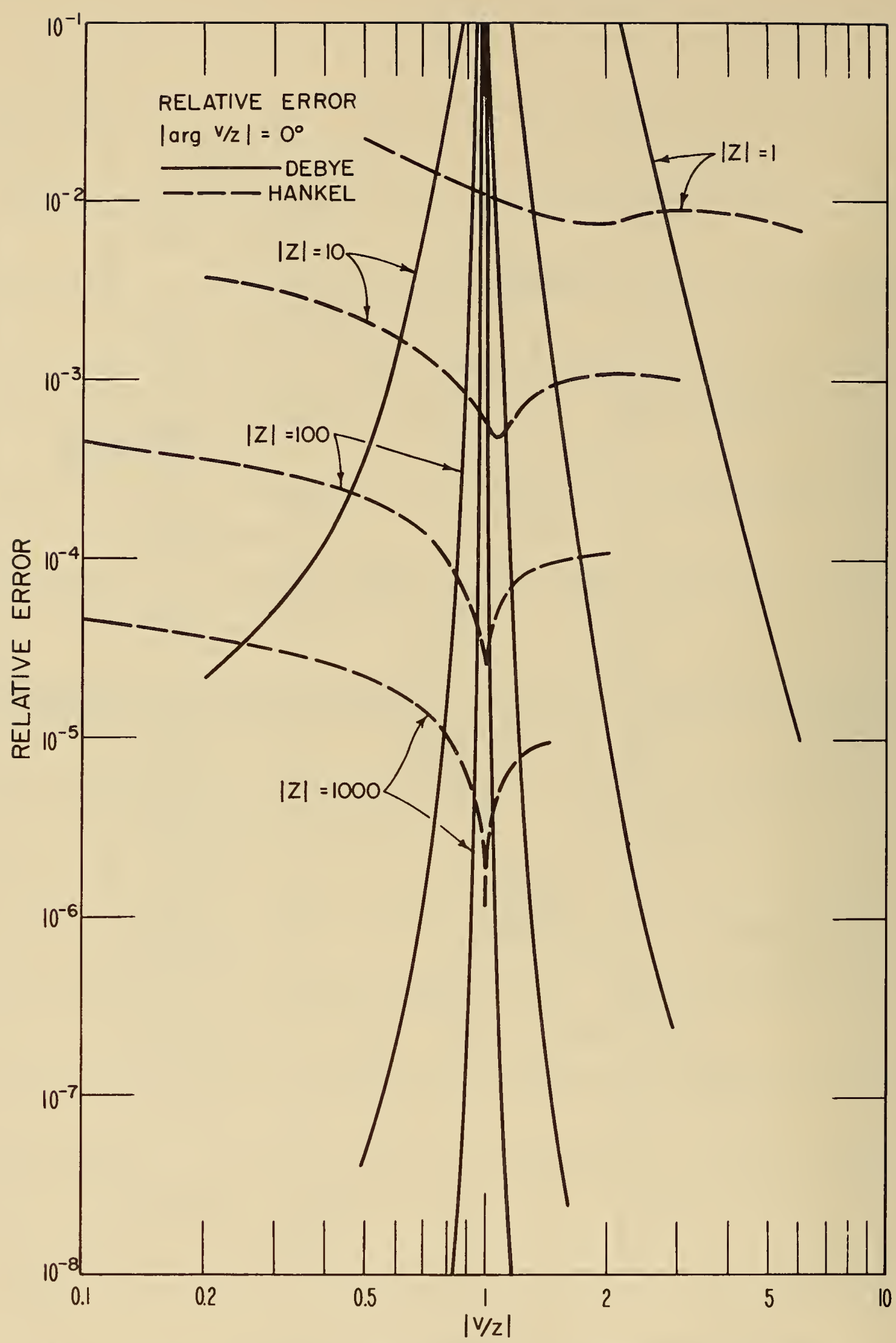

Figure 2. Relative errors of the Debye and Hankel approximations for $|\arg v / z|=0^{\circ}$, for various $|z|$. 


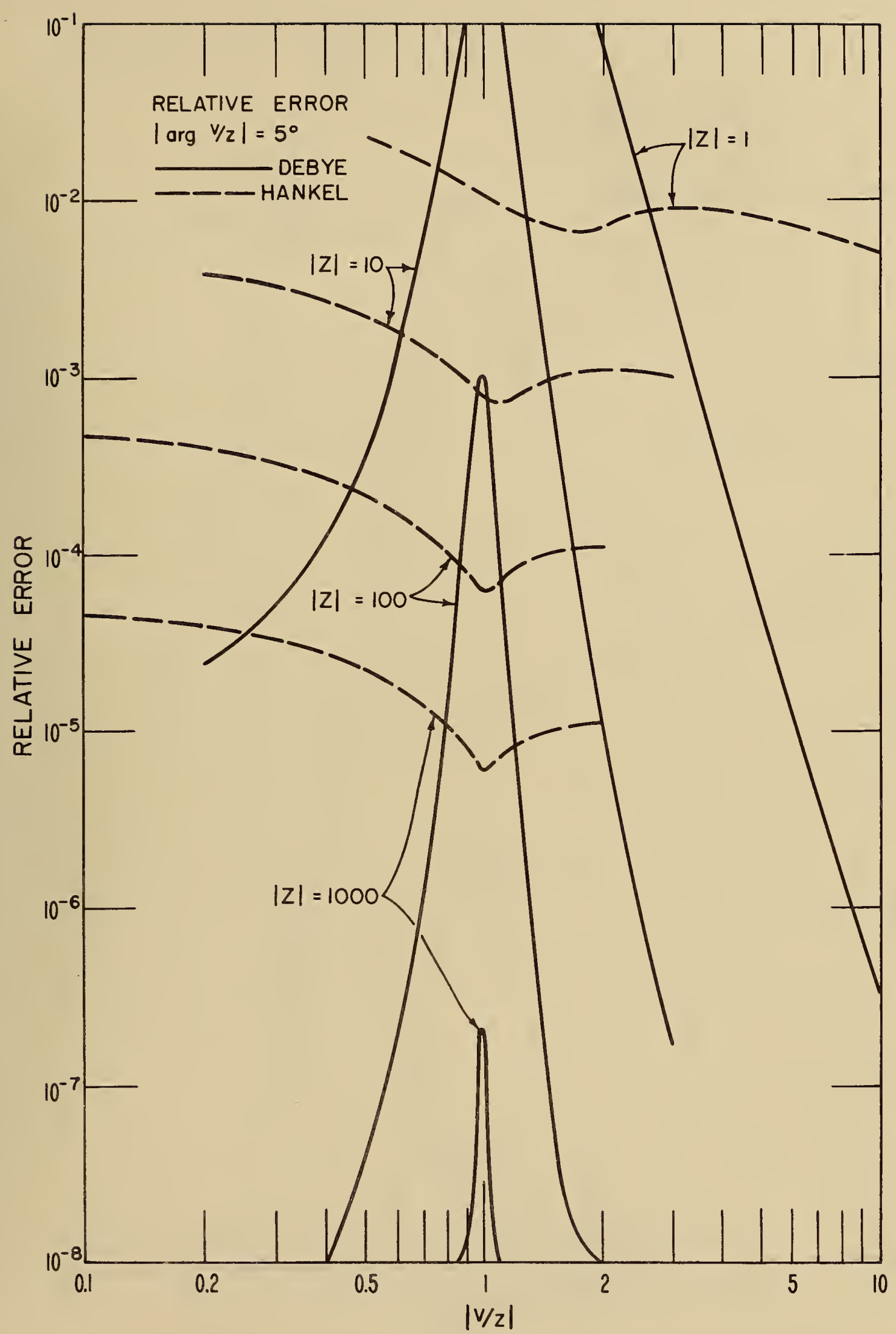

Figure 3. Relative errors of the Debye and Hankel approximations for $|\arg v / z|=5^{\circ}$, for various $|z|$. 


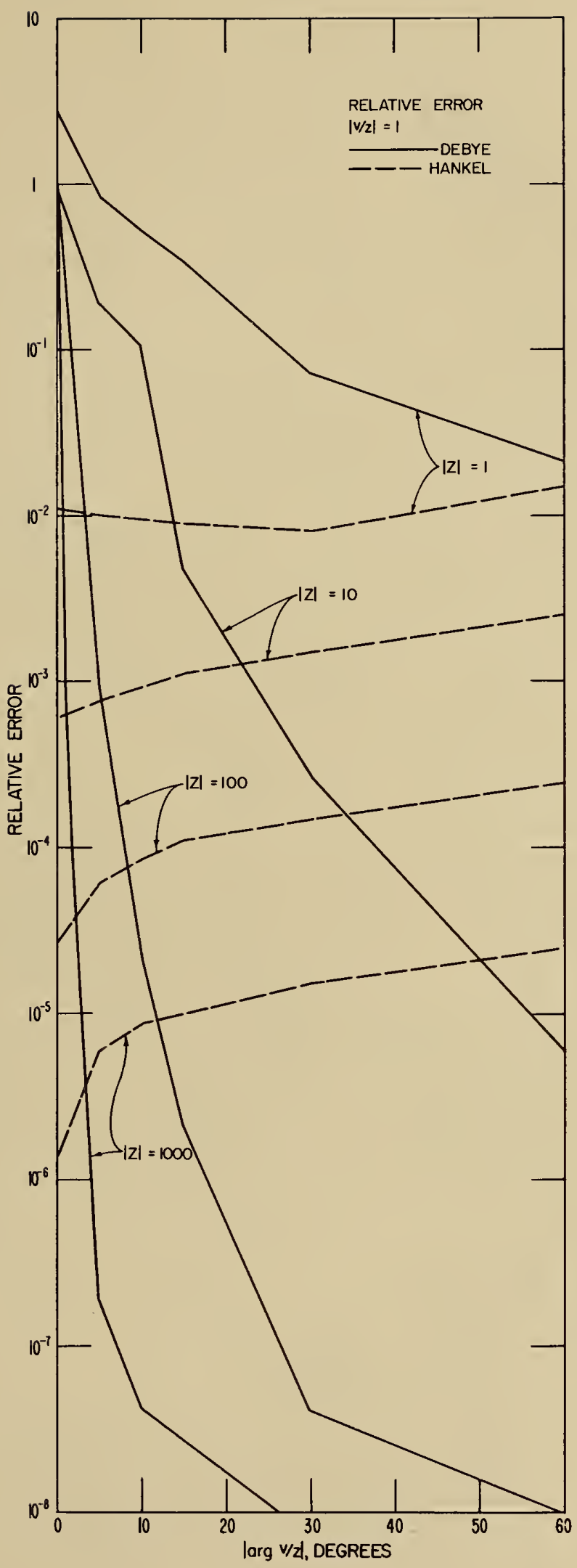

Figure 5. Relative errors of the Debye and Hankel approximations for $|\mathrm{v} / \mathrm{z}|=1$, as a function of $|\arg \mathrm{v} / \mathrm{z}|$, for various $|\mathrm{z}|$. 


